\title{
Overexpression of Enterococcus faecalis elr operon protects from phagocytosis
}

\author{
Naima G. Cortes-Perez ${ }^{1,2,5}$, Romain Dumoulin ${ }^{1,2}$, Stéphane Gaubert ${ }^{1,2}$, Caroline Lacoux ${ }^{1,2}$, Francesca Bugli ${ }^{3}$, \\ Rebeca Martin ${ }^{1,2}$, Sophie Chat ${ }^{1,2}$, Kevin Piquand ${ }^{1,2}$, Thierry Meylheuc ${ }^{1,2}$, Philippe Langella ${ }^{1,2}$, Maurizio Sanguinetti ${ }^{3}$, \\ Brunella Posteraro ${ }^{4}$, Lionel Rigottier-Gois ${ }^{1,2}$ and Pascale Serror ${ }^{1,2^{*}}$
}

\begin{abstract}
Background: Mechanisms underlying the transition from commensalism to virulence in Enterococcus faecalis are not fully understood. We previously identified the enterococcal leucine-rich protein A (EIrA) as a virulence factor of E. faecalis. The elrA gene is part of an operon that comprises four other ORFs encoding putative surface proteins of unknown function.

Results: In this work, we compared the susceptibility to phagocytosis of three E. faecalis strains, including a wild-type (WT), a $\triangle$ elrA strain, and a strain overexpressing the whole elr operon in order to understand the role of this operon in E. faecalis virulence. While both WT and $\Delta$ elrA strains were efficiently phagocytized by RAW 264.7 mouse macrophages, the elr operon-overexpressing strain showed a decreased capability to be internalized by the phagocytic cells. Consistently, the strain overexpressing elr operon was less adherent to macrophages than the WT strain, suggesting that overexpression of the elr operon could confer E. faecalis with additional anti-adhesion properties. In addition, increased virulence of the elr operon-overexpressing strain was shown in a mouse peritonitis model.
\end{abstract}

Conclusions: Altogether, our results indicate that overexpression of the elr operon facilitates the E. faecalis escape from host immune defenses.

Keywords: Enterococcus faecalis, Macrophage, elrA, elr operon

\section{Background}

As a natural inhabitant of the oral cavity, gastrointestinal tract, and female vaginal tract in humans, Enterococcus faecalis is normally considered a nonpathogenic microorganism. However, it is a common opportunistic pathogen in immunocompromised patients, causing nosocomial infections. While our current understanding of the mechanisms that lead to the lifestyle shift from commensalism to virulence in enterococci remains an emerging area of research, the pathogenesis of E. faecalis is clearly nonetheless a complex multifactorial process that currently remains poorly understood. In this regard, we have previously identified the enterococcal leucine-rich protein A (ElrA), a protein that possesses a leucine-rich repeat (LRR) domain and

\footnotetext{
* Correspondence: pascale.serror@jouy.inra.fr

'INRA, UMR1319 Micalis, Jouy-en-Josas, France

${ }^{2}$ AgroParisTech, UMR1319 Micalis, Jouy-en-Josas, France

Full list of author information is available at the end of the article
}

a carboxy-terminal WxL domain, which promotes noncovalent association to the bacterial surface [1]. ElrA is encoded by the elr operon, which encodes two other WxL surface proteins, a small LPXTG-motif protein and a putative transmembrane protein proposed to form cell surface complexes [1-4]. Expression of the elr operon is under the control of the positive regulator $\operatorname{elr} R[4,5]$. The elrA gene is poorly expressed in vitro, but it can be induced by complex biological milieu such as serum or urine, which suggests the tightly regulated control of elrA expression in response to in vivo signals $[5,6]$. Previously, we showed that inactivation of the elrA gene resulted in significantly reduced virulence in a mouse model of peritonitis [4]. We also observed reduced secretion of interleukin-6 (IL-6, a pro-inflammatory cytokine) upon in vivo infection with the $\triangle e l r A$ mutant strain and we hypothesized that ElrA may be involved in this

Ciomed Central

(c) 2015 Cortes-Perez et al.; licensee BioMed Central. This is an Open Access article distributed under the terms of the Creative Commons Attribution License (http://creativecommons.org/licenses/by/4.0), which permits unrestricted use, distribution, and reproduction in any medium, provided the original work is properly credited. The Creative Commons Public Domain Dedication waiver (http://creativecommons.org/publicdomain/zero/1.0/) applies to the data made available in this article, unless otherwise stated. 
modulation, by stimulating host immune cells to counteract E. faecalis infection [4].

Macrophages are potent antigen presenting cells that play a key role in initiating an immune response against invading bacteria. In turn, some pathogens have evolved strategies in order to circumvent macrophage functions [7]. Previous studies have shown that $E$. faecalis can survive in peritoneal macrophages better than other non-pathogenic bacteria $[8,9]$. In addition, it possesses mechanisms permitting escape from murine or human macrophages $[8,10$, 11]. E. faecalis cell wall glycopolymers play a key role in the resistance to phagocytosis. In particular, capsular polysaccharide serotypes $\mathrm{C}$ and D contribute to complement evasion [12, 13] and rhamnopolysaccharide Epa protects from phagocytic killing [13, 14], most likely by preventing uptake by macrophages as we recently showed in zebrafish model [15].

In the present study, we sought to evaluate whether the expression of elrA alone or that of the entire elr operon most influences the capability of $E$. faecalis to be phagocytized by the RAW 264.7 mouse macrophages in vitro. To circumvent the aforementioned low level of elrA expression in vitro, a genetically modified E. faecalis strain harboring a constitutive promoter upstream of the elr operon $\left(\mathrm{P}^{+}\right.$-elrA-E) was constructed. The ability of this elr-overexpressing strain to be internalized was compared with a wild-type strain of E. faecalis, and with different isogenic-elr mutant strains, obtained by genetic manipulation of the E. faecalis $\mathrm{P}^{+}$-elrA-E strain.

\section{Results and discussion}

\section{Production of ElrA requires other gene(s) of the elr operon}

As previously discussed, E. faecalis ElrA protein is poorly expressed in vitro, but induced in vivo and is particularly important for $E$. faecalis virulence $[4,5]$. Moreover, this protein could not be detected by Western blot experiments in total protein extracts prepared from E. faecalis wild-type strain OG1RF (WT) [4, 5]. Located immediately downstream of elrA in the five-gene elr operon (see Materials and Methods and Fig. 1), there is a gene encoding a small protein with an LPXTG anchor motif (ElrB), followed by two further proteins each possessing a carboxy-terminal WxL anchor motif (ElrC and ElrD), and finally a putative transmembrane protein (ElrE), a member of the DUF916 protein family [4]. A BLAST (Basic Local Alignment Search Tool) analysis performed on the sequence of elrABCDE using the NCBI non-redundant protein sequence (nr) database revealed novel orthologs for the five proteins (ElrA-ElrE). The corresponding best matches for ElrA were observed with the hypothetical protein WP_022792020.1 of Weissella halotolerans (34\% identity and $49 \%$ homology between residues 85 to 718 of ElrA and residues 8 to 680 of WP_022792020.1) and the hypothetical protein UC3_01347 of Enterococcus phoeniculicola (36 \% identity and $54 \%$ homology between residues 1 to 471 of ElrA and residues 1 to 467 of UC3_01347), followed by InlA of L. monocytogenes as initially reported [4]. Orthologs of proteins ElrB to ElrE were detected in various species with the respective best matches for $E$ nterococcus pallens (ElrB), Enterococcus phoeniculicola (ElrC), Lactococcus garvieae and Enterococcus avium (ElrD), Carnobacterium divergens and Carnobacterium maltaromaticum (ElrE). Proteins possessing WxL domains, cognate putative transmembrane and LPXTG proteins have been proposed to form multicomponent complexes on the bacterial surface [2]. This hypothesis is supported by the recent work of Galloway-Pena et al. who showed interaction between E. faecium locus A-encoded WxL proteins and the cognate transmembrane protein in vitro [3]. In this context, the organization of the elr operon suggests that the four proteins (ElrB-ElrE) have a function related to ElrA. To address the role of ElrA in vitro while maintaining Elr protein stoichiometry, we engineered

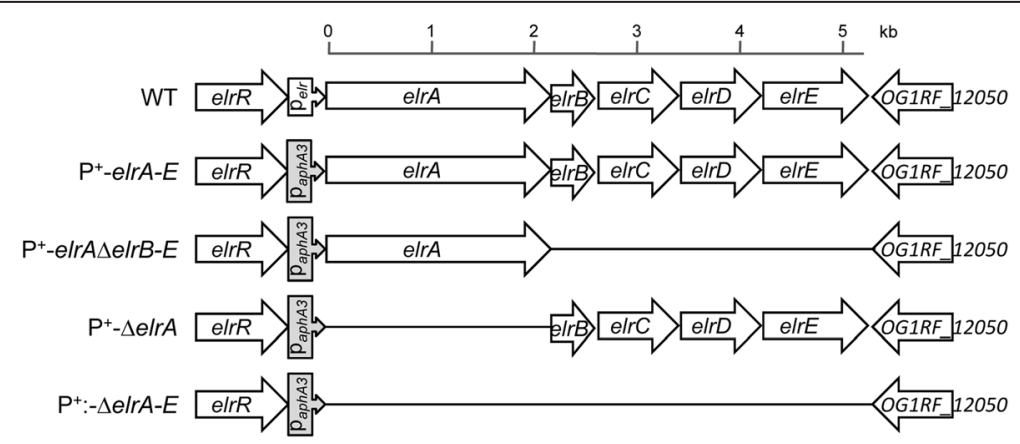

Fig. 1 Schematic representation of the elrA operon in strains used. In E. faecalis WT elrA is followed by four genes encoding proteins of unknown function (OGIRF_12054 or elrB to OGIRF_12051 or elrE). The gene products are all predicted secreted proteins with an amino-terminal signal peptide. ElrA, ElrC and ElrD display a C-terminal WxL domain. ElrB possess a carboxy-terminal LPXTG anchor. ElrE belongs to the DUF916 family protein and has a predicted C-terminal transmembrane anchor. In $\mathrm{P}^{+}$-elrA-E the natural elrA promoter was replaced by the constitutive promoter of the kanamycin resistance gene $\left(\mathrm{P}_{a p h A 3}\right)$. The $\mathrm{P}^{+}-$elrA-E strain was used as recipient for all mutant constructions 
an E. faecalis strain overexpressing the whole elr operon. This strain, E. faecalis $\mathrm{P}^{+}$-elrA-E, was generated by replacement of the elr operon promoter region by the E. faecalis $\mathrm{P}_{a p h A 3}$ constitutive promoter $\left(\mathrm{P}^{+}\right.$strain, see Material and Methods) [4, 16] (Fig. 1). Subsequently, to explore the role of ElrB-ElrE in ElrA function, the $\mathrm{P}^{+}$-elrA-E strain was used to generate: $\left.\mathrm{i}\right)$ a strain expressing the elr operon but without elrA: E. faecalis $\mathrm{P}^{+}-\Delta e \operatorname{lr} A$, ii) a strain overexpressing only elrA: E. faecalis $\mathrm{P}^{+}$-elrA- $\Delta$ elr $B-E$ strain, and iii) a strain where the entire elr operon was inactivated: E. faecalis $\mathrm{P}^{+}-\Delta e l r A-E$ (Fig. 1). Growth of the three strains was comparable (data not shown), indicating that neither expression of elr operon nor parts of it impacted bacterial growth under the conditions tested.

We first tested ElrA production in each of the different strains by Western blot analysis. As expected, ElrA was not detected in protein extracts prepared from WT, $\mathrm{P}^{+}-\Delta e l r A$, or $\mathrm{P}^{+}-\Delta e l r A-E$ culture. Strikingly, protein extracts prepared from $\mathrm{P}^{+}-e l r A-E$ strain revealed a band of the expected size for ElrA (80-kDa, Fig. 2A), confirming that the endogenous $\mathrm{P}_{\text {elrA }}$ promoter is inactive in vitro, and that its replacement by a constitutive promoter allows expression of elrA in vitro. No ElrA was detected in protein extracts prepared from the $\mathrm{P}^{+}$-elr $A-\Delta e \operatorname{lr} B-E$ strain (Fig. 2A), suggesting an important role for at least one of the four other proteins present in the elr operon in either the production or stability of ElrA. To corroborate this hypothesis and study elrA transcription in the $\mathrm{P}^{+}$-elrA- $\Delta$ elrB-E strain, elr $A$ transcripts were analyzed by Northern blotting hybridization using total RNA prepared from the WT, $\mathrm{P}^{+}-e l r A-E$ and $\mathrm{P}^{+}$-elrA- $A$ elr $B-E$ strains. As expected, elrA transcript was not detected in the WT strain by Northern blotting under laboratory growth conditions, confirming our previous results $[4,5]$. Similar analyses in respect of the $\mathrm{P}^{+}-e \operatorname{lr} A-E$ and $\mathrm{P}^{+}$-elrA- $\triangle$ elrB-E overexpression strains resulted in strong hybridization signals corresponding to transcripts, of sizes of $\sim 5$ and $2.4 \mathrm{~kb}$, corresponding to the predicted fulllength, and the elrBCDE-deleted elr operon transcripts, respectively (Fig. 2B). Detection of elr $A$ transcripts in $\mathrm{P}^{+}$-elr $A-\Delta e \operatorname{lr} B-E$ strain strongly indicates a post-transcriptional control of ElrA expression, confirming the important role of at least one of the four other elr operon genes for either ElrA production or stabilization.

\section{Overexpression of elr operon impairs phagocytosis}

We then explored the effect of elr operon overexpression on the E. faecalis interaction with macrophages by monitoring phagocytosis of GFP-labeled E. faecalis strains by RAW cells using flow cytometry analysis. Firstly, we evaluated the phagocytosis dynamics of the E. faecalis WT strain at different multiplicities of infection (MOI, data not show) and decided to use a MOI of 1:100 in which approximately $58 \% \pm 11$ (mean \pm SEM after three
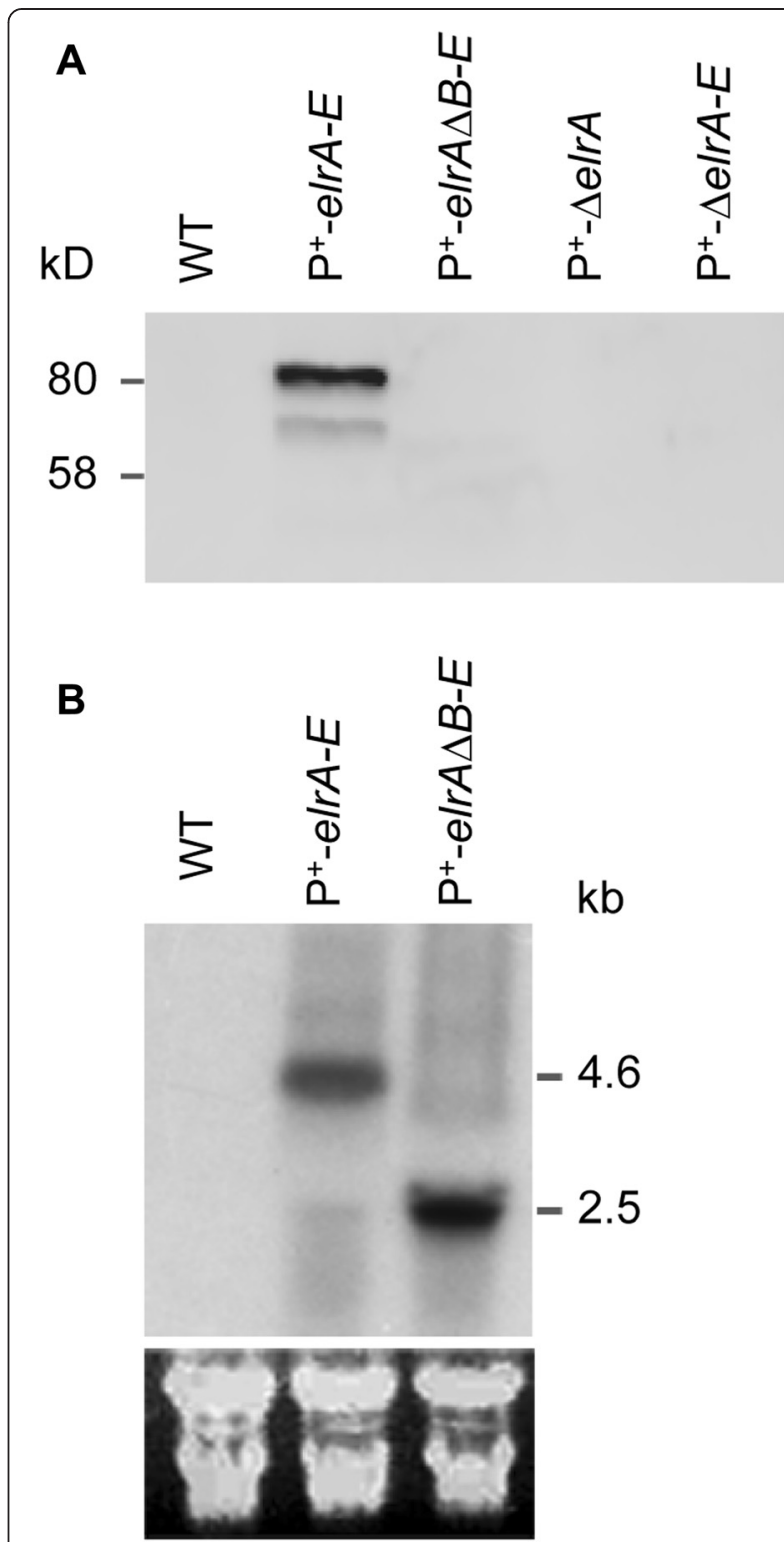

Fig. 2 Detection of ElrA protein and elr transcript. a) Western blot analysis of total protein extracts from WT and mutant strains of E. faecalis, that was performed using a $12 \%$ SDS-PAGE and polyclonal rat anti-ElrA antibodies, is shown. Band at $\sim 80 \mathrm{kD}$ corresponds to the predicted size of ElrA, whereas the additional band represents a degradation product. b) Northern blot analysis of elr operon performed with $\sim 40 \mu \mathrm{g}$ of total RNA which was extracted from exponentially growing cells. Names of strains analyzed are indicated at the top of each lane. Probes used were elrA-specific oligonucleotide probes. The estimated length of transcripts that agrees with their predicted sizes is shown on the right. Below, ribosomal RNAs were used as loading controls

independent experiments each one in triplicate) of macrophages were GFP positive after $30 \mathrm{~min}$ of interaction. This value was used as reference (nominal $100 \%$ ) in order to estimate the phagocytosis index (PI) of the different $E$. faecalis mutant strains (see Materials and Methods). Operon inactivation $\left(\mathrm{P}^{+}-\Delta e l r A-E\right)$ did not 


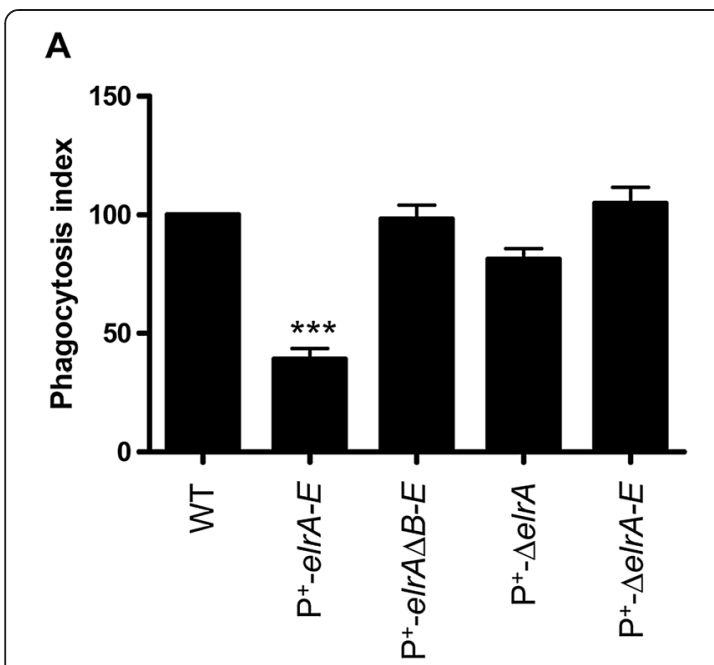

B

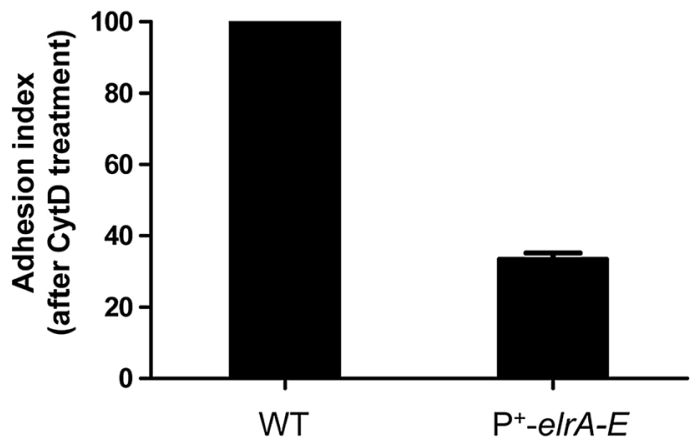

C

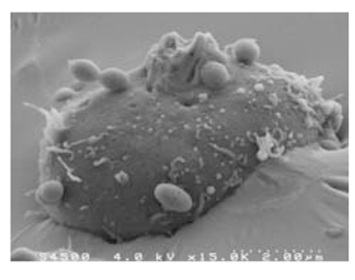

WT

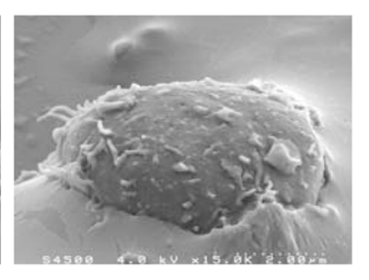

$\mathrm{P}^{+}-$elrA-E

Fig. 3 Phagocytosis of isogenic strains overexpressing full-length or partially deleted elr operon by RAW macrophages. a) For all $E$. faecalis strains tested, the phagocytosis index (PI) was calculated as average \pm SEM from three independent experiments. Statistical significance was measured by ANOVA and Dunnett's multiple comparison test, ${ }^{* *} P<0.001$. b) Adhesion index (Al) of E. faecalis strains after treatment with cytochalasin D. Al was calculated as follows: $\mathrm{Al}=\%$ of GFP-labeled macrophages after infection with the mutant strain $X$ 100/\% of GFP-labeled macrophages after infection with the WT strain. Shown is the mean \pm SEM from two independent experiments performed in duplicate. c) Scanning electronic microscopy (SEM) showing E. faecalis adhesion. Micrographs of macrophages infected for 30 min with $E$. faecalis strains observed by electron scanning microscopy. The micrographs are representative of two independent experiments affect bacterial uptake when compared to the WT strain $(105 \pm 6.7 \%$, Fig. 3A). In contrast, a significant reduction of phagocytosis was observed with $\mathrm{P}^{+}$-elrA-E strain ( $\mathrm{PI}=$ $39 \% \pm 4.4 ; P<0.0001$, Fig. 3A). Although constitutive expression of the four other operon proteins $\left(\mathrm{P}^{+}-\Delta e l r A\right.$ strain) appeared to reduce phagocytosis (PI $=81.3 \% \pm$ 4.4), this reduction was not statistically significant (Fig. 3A). As expected, given that the $\mathrm{P}^{+}$-elrA- $\Delta e \operatorname{lr} B-E$ strain does not appear to produce ElrA (Western blot results, Fig. 2A), no difference in phagocytosis was observed when this strain was compared to the WT strain (PI $=98.2 \% \pm 5.8$ ) (Fig. 3A). Lower levels of uptake by phagocytosis of the strain $\mathrm{P}^{+}$-elrA-E compared to the WT was confirmed by double-labeling fluorescence microscopy analysis (data not shown). These results support a link between the expression of elr operon and the uptake of E. faecalis.

Overexpression of elr operon modifies bacterial adhesion Phagocytosis is initiated with the recognition of ligands on bacterial cell surfaces by receptors including scavenger receptors, glucan receptors, and integrins present on the membrane of macrophages, which leads to bacteria engulfment via an actin-dependent mechanism. To test whether the impairment of phagocytosis seen for the $\mathrm{P}^{+}-e l r A-E$ strain correlated with reduced adhesion of the bacterium to macrophage cells, we used cytochalasin D (CytD), which inhibits phagocytosis, but does not prevent the initial step of bacterial adhesion $[17,18]$. Macrophages were therefore infected (as described above for the phagocytosis test) with either WT or $\mathrm{P}^{+}$-elrA-E strains in the presence or absence of CytD, and the percentages of $\mathrm{GFP}^{+}$macrophages were measured by flow cytometry analysis (uninfected macrophages were used as negative control). Comparison of forward scatter (FSC) and side scatter (SSC) values from uninfected cells (CytD treated or untreated) confirmed that macrophages were not altered by CytD (Additional file 1: Figure S1). As shown in Fig. 3B, $\mathrm{P}^{+}-e l r A-E$ strain was $60 \%$ less adherent to macrophages than the WT strain. These results are in agreement with scanning microscopy observations of infected macrophages, that showed a sharp contrast between adhesion of WT and $\mathrm{P}^{+}$-elrA-E strains (Fig. 3C).

Because proteins encoded by the elr operon demonstrate characteristics of surface proteins (WxL, and LPXTG motifs) and could form a surface complex, we hypothesized that overexpression of elr operon could result in the formation of surface structures, which in turn resulted in the inhibition of phagocytosis as observed in vitro. Analyses of bacterial strains using transmission electron microscopy (thin sections and negative staining) and scanning electron microscopy revealed no differences at the surface structure level between the WT and the elr operon-overexpressing 
strain (data not shown). This indicated that no major structural modification was detected under the tested conditions. Since high expression levels of surface proteins can modify physicochemical properties of bacterial cell surface such as charge or hydrophobicity [19, 20], we compared the affinity of bacterial cells of WT and $\mathrm{P}^{+}$-elrA-E strains to the solvents using a MATS test as described by BellonFontaine et al. [21]. Both strains exhibited similar affinity for the apolar solvents decane $(\sim 40 \%)$ and hexadecane $(\sim 30 \%)$ and for the acidic solvent chloroform ( 70 \%), indicating no major changes of the surface hydrophobicity upon elr overexpression. In turn, the affinity of the strain $\mathrm{P}^{+}$-elrA-E for the basic solvent ethyl acetate $(\sim 35 \%)$ increased significantly compared to the WT $(<1 \%)$, indicating that expression of elr operon enhances the negative charge of the bacterial cells. Thus we hypothesize that poor adhesion of strain $\mathrm{P}^{+}$-elrA-E may result from repulsive forces between the negatively charged macrophage membrane and bacterial surface, which is loaded with Elr proteins.

\section{Overexpression of elr operon increases $E$. faecalis virulence}

Inactivation of ElrA reduces virulence in a mouse model of peritonitis [4] and we show that overexpression of elr operon impairs phagocytosis in vitro. We hypothesized that overexpression of elr may enhance dissemination, and thus E. faecalis virulence. To test this hypothesis, we assessed the survival of mice following peritoneal infection with WT, $\mathrm{P}^{+}-e l r A-E$, or $\Delta e l r A$ strains. Mice were injected with three different doses of WT or mutant strains, and the mortality rates were compared. No differences in mortality levels were found when mice were infected with $10^{9} \mathrm{CFU}$ of WT or mutant strains (data not shown). Interestingly, mortality was significantly increased for mice infected with $3 \times 10^{8}$ and $1 \times 10^{8} \mathrm{CFU}$ of $\mathrm{P}^{+}-e l r A-E$ strain compared to WT and $\triangle e l r A$ strains at $72 \mathrm{~h}$ post-infection (Fig. 4). Eighty five percent of the mice infected with $3 \times 10^{8} \mathrm{CFU}$ of $\mathrm{P}^{+}$-elrA-E strain died, whereas $45 \%$ and $10 \%$ mice died when infected with the WT and $\triangle e l r A$ strains, respectively $(P=0.049$ and

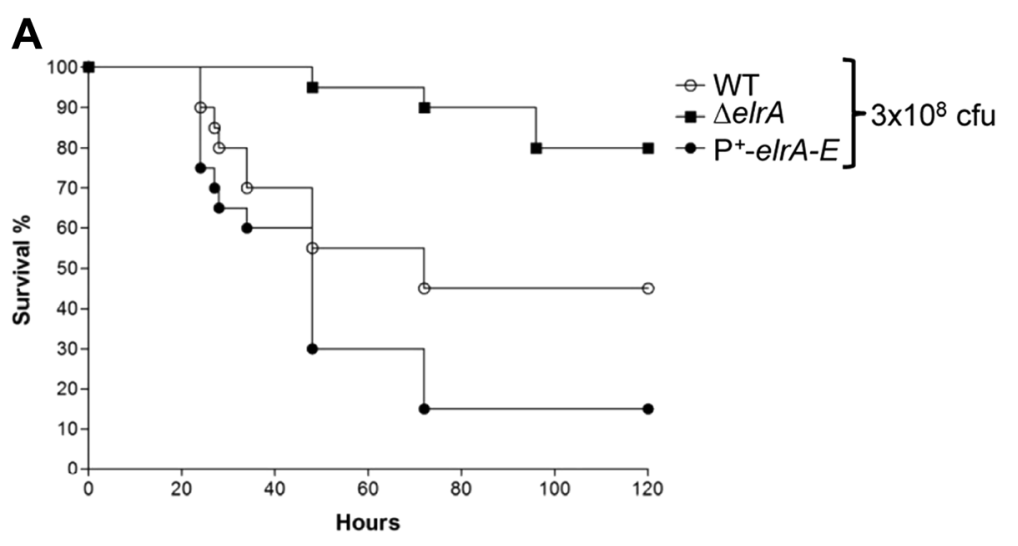

\section{B}

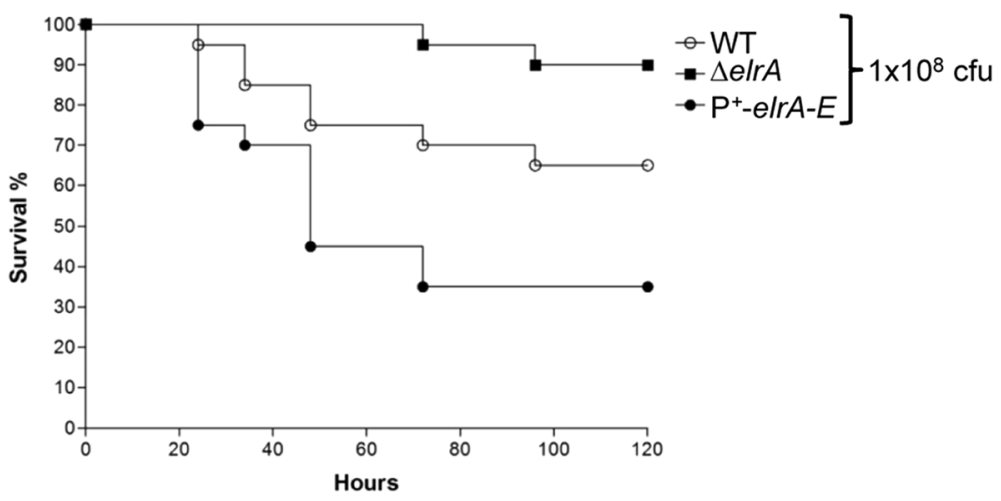

Fig. 4 Effect of overexpression of elr operon on E. faecalis virulence. Kaplan-Meier survival analysis in a mouse peritonitis model with the E. faecalis WT strain (open circles), the $\triangle$ elrA strain (squares), and the $\mathrm{P}^{+}$-elrA-E strain (closed circles). A total of 10 mice were infected intraperitoneally with $\sim 3 \times 10^{8}$ (a) or $\sim 1 \times 10^{8}$ (b) CFU of each strain. For pairwise comparisons of $\mathrm{P}^{+}$-elrA-E / WT and $\mathrm{P}^{+}$-elrA-E / WT, $P$ values were $<0.05$ for each inoculum 
$P<0.0001$ ) (Fig. 4A). Similarly, 65, 30, and $5 \%$ of the mice infected with $1 \times 10^{8} \mathrm{CFU}$ of $\mathrm{P}^{+}-e \operatorname{lr} A-E$, WT, and $\triangle e l r A$ strains died, respectively $(P=0.044$ and $P<0.0001)$ (Fig. 4B). These results show that overexpression of elr operon increases $E$. faecalis virulence. We also compared the dissemination of the WT, $\mathrm{P}^{+}$-elrA-E, or $\triangle e l r A$ strains in organs of mice at $24 \mathrm{~h}$ postinfection by determining bacterial loads (Fig. 5A). A 0.70- and 1.79- $\log 10$ increase in the bacterial counts in the liver and spleen, respectively, were observed for the $\mathrm{P}^{+}-e l r A-E$ compared to the WT and $\triangle e l r A$ strains, respectively, when mice were challenged with inocula of $1 \times 10^{8} \mathrm{CFU}$. Similar trends were observed with inocula of $3 \times 10^{8} \mathrm{CFU}$ (1.05- and $0.93-\log 10$, respectively), although to a somewhat lesser extent (Fig. 5B). These results indicate that the virulence phenotype correlates with higher dissemination of the strain $\mathrm{P}^{+}-e \operatorname{lr} A-E$. The correlation between increased virulence and avoidance of phagocytosis observed in vitro corroborates our hypothesis that elr operon may be involved in the evasion of the immune response by $E$. faecalis. We previously linked the attenuated virulence of an elrA deficient strain with the decreased organ burden and survival in peritoneal macrophages using an in vivo-in vitro infection model [4]. These new data suggest that expression of $\operatorname{elr} A$ and/or elr operon contributes to the escape of E. faecalis from phagocytosis in vivo, promoting dissemination and enhancing virulence of the pathogen.
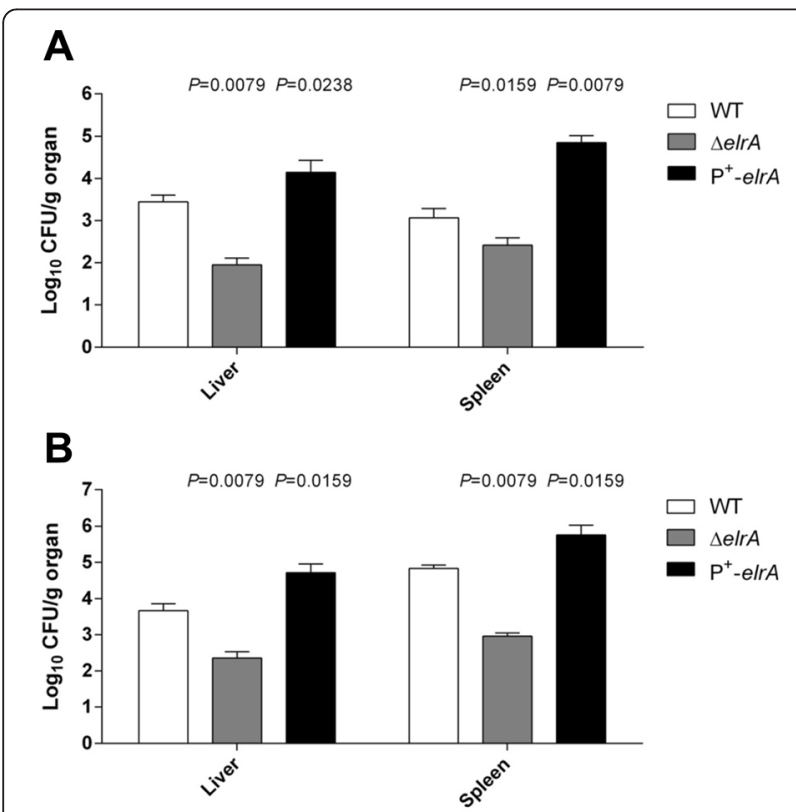

Fig. 5 Overexpression of elr operon in E. faecalis increases bacterial dissemination in mice. E. faecalis organ burden in 10 mice were infected intraperitoneally with $\sim 3 \times 10^{8}$ (a) or $\sim 1 \times 10^{8}$ (b) CFU of each strain. The results represent the means and standard deviations of the number of bacteria able to colonize the spleen and liver at $24 \mathrm{~h}$ postinfection

\section{Discussion}

Previous studies have shown that E. faecalis survives into peritoneal macrophages better than non-pathogenic bacteria [8]. Since then, E. faecalis virulence factors able to interfere with uptake and survival in macrophages have been described [22]. We previously linked the attenuated virulence of an E. faecalis strain deleted for $\operatorname{elr} A$ with decreased organ burden and survival in peritoneal macrophages [4]. In this study, we show that overexpression of elr operon by E. faecalis confers resistance to phagocytosis by interfering with bacterial adhesion to macrophages. We also correlated E. faecalis avoidance of phagocytosis observed in vitro with increased virulence and dissemination in a mouse peritonitis model. These data contrast with our previous report that WT and $\Delta e l r A$ strains were evenly phagocytosed [4]. Nevertheless, these studies are difficult to compare since macrophage infections were performed differently (i.e. in vivo versus in vitro infection and duration of infection). Moreover, the expression level of Elr proteins in vivo is unknown. The tight control of expression of the elr operon suggests that the operon may be required in specific conditions that remain to be identified $[4,5]$. The 162-fold increased level of erlA transcript in E. faecalis strain MMH594 grown in urine [6], supports that expression of Elr proteins may vary in response to hostderived cues. We assume that elr operon may enhance E. faecalis virulence by promoting initial dissemination in the host after escape of bacteria from phagocytosis, but also by contributing to E. faecalis survival within infected macrophages depending on the tissues or cell types encountered by E. faecalis. From this study we propose that high-level expression of elr operon may, in some circumstances, occur in vivo and promotes escape of $E$. faecalis from phagocytosis.

The present study also revealed that ElrA requires at least one other elr gene to be expressed at a detectable level and confirmed that elrA gene is cotranscribed with the other elr genes [4]. The elr operon is a typical gene cluster of $\mathrm{WxL}$ surface proteins that associate non-covalently to the peptidoglycan of low-GC gram-positive bacteria. The operonic organization of the elr operon and the need of at least one other protein encoded by elr operon for ElrA production in vitro further support the hypothesis that cell-surface proteins, encoded by the elr operon, may participate in the formation of a multicomponent complex at the surface as it has been previously proposed [1, 2, 4]. Based on recent work by Galloway-Pena et al. who showed that WxL and DUF916 proteins interact in vitro [3], we believe that ElrA may be protected from degradation by interacting with at least another elr-encoded protein. If neither surface appendages nor modification could be observed upon overexpression of elr operon, other experiments are needed to establish if elr operon drives the formation of a surface 
complex in E. faecalis. Nevertheless, overexpression of Elr proteins seems to increase the negative charge of the bacterial surface, suggesting that E. faecalis evasion of phagocytosis by immune cells is driven by electrostatic repulsion. Even if elr overexpression emphasizes the steric or charge hindrance by Elr proteins in vitro, one cannot exclude that similar physicochemical changes occur in vivo in response to environmental cues [6], and confers to the E. faecalis cells anti-adhesion properties that promote escape from phagocytosis. These in vitro findings are reminiscent of the acidic LRR protein Slr from Streptococcus pyogenes that is involved in phagocytosis evasion [23], probably by enhancing the anti-adhesive properties of streptococcal cells. Another possibility would be that high level of Elr proteins sterically hinders $E$. faecalis-associated molecular patterns important for recognition by scavenger receptors. Altogether, this work shows that expression of elr operon contributes to the escape of E. faecalis from phagocytosis, promoting dissemination and enhancing virulence of the pathogen. Further investigations will focus on characterizing the precise role of each of the Elr proteins.

\section{Conclusions}

In summary, this work shows that high-level expression of elr operon by $E$. faecalis increases virulence and confers resistance to phagocytosis, probably through charge repulsion. Consistently, the strain expressing elr operon displays stabilization of ElrA, further supporting that Elr proteins form an extracellular protein complex as part of the virulence process. Structural and functional characterization of the Elr proteins will help to understand E. faecalis pathogenesis and provide clues on WxL- and associated proteins of low-GC Gram-positive bacteria.

\section{Methods \\ Reagents}

All reagents were obtained from Sigma-Aldrich (St. Louis, $\mathrm{MO})$, unless otherwise stated.

\section{Bacterial strains and plasmids}

Bacterial strains and plasmids used in this work are listed in Table 1. E. faecalis strains were grown in M17 medium supplemented with $0.5 \%$ glucose (GM17) at $37{ }^{\circ} \mathrm{C}$ without aeration. Escherichia coli strains were grown aerobically in Luria-Bertani medium at $37^{\circ} \mathrm{C}$. Plasmid constructions were first established in E. coli TG1 strain and then transferred into $E$. faecalis by electrotransformation using a Bio-Rad Gene Pulser Electroporator (Bio-Rad Laboratories). E. faecalis strains expressing green-fluorescent protein (GFP) were obtained by electroporation with pMV158-GFP plasmid [24]. Recombinant bacteria were selected by the addition of antibiotics as follows: for E. faecalis chloramphenicol $4 \mu \mathrm{g} / \mathrm{ml}$, tetracycline $4 \mu \mathrm{g} / \mathrm{ml}$ and erythromycin
Table 1 Strains and plasmids used in this work

\begin{tabular}{|c|c|c|}
\hline Strain & Designation relevant characteristics & $\begin{array}{l}\text { Source or } \\
\text { Reference }\end{array}$ \\
\hline \multicolumn{3}{|l|}{ E. faecalis } \\
\hline WT & $\begin{array}{l}\text { Fus }{ }^{r} \text { Rif'; plasmid-free wild-type } \\
\text { strain }\end{array}$ & {$[35]$} \\
\hline$\Delta e l r A$ & OG1RF $\triangle e l r A$ & {$[4]$} \\
\hline$P^{+}-e l r A-E$ & OG1RF $P_{a p h A 3:: e l r A-E}$ & This work \\
\hline $\mathrm{P}^{+}-\triangle e l r A$ & OG1RF P $P_{a p h A 3: . \triangle e l r A}$ & This work \\
\hline $\begin{array}{l}P^{+}-e l r A- \\
\Delta e l r B-E\end{array}$ & OG1RF $P_{a p h A 3}:$ :elrA- $\triangle$ elrB-E & This work \\
\hline $\mathrm{P}^{+-\Delta e l r A-E}$ & OG1RF P $P_{a p h A 3: .} \Delta e l r A-E$ & This work \\
\hline \multicolumn{3}{|l|}{ E. coli } \\
\hline TG1 & $\begin{array}{l}\text { supE hsdD5 thi ( } \triangle \text { lac-proAB) } \\
\mathrm{F}^{\prime}(\text { traD36 proAB-lacZ } \triangle M 15)\end{array}$ & {$[36]$} \\
\hline 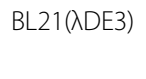 & $\begin{array}{l}\left.\mathrm{F}^{-} \text {ompT gal dcm hsdSB( } \mathrm{rB}^{-} \mathrm{mB}^{-}\right) \\
\lambda \mathrm{DE} 3\end{array}$ & {$[37]$} \\
\hline \multicolumn{3}{|l|}{ Plasmids } \\
\hline pACYC177 & $A m p^{r}, K^{r}{ }^{r}$, ori p15A & [38] \\
\hline pET2817 & $\begin{array}{l}\text { Ampr', ori colE1, T7 promoter, } \\
\text { His-Tag } \\
\text { coding sequence }\end{array}$ & [39] \\
\hline $\begin{array}{l}\text { PGEM-T } \\
\text { easy }\end{array}$ & $\begin{array}{l}\text { Ampr, ori ColE1, linearized with } \\
3^{\prime} T \text { overhangs }\end{array}$ & Promega \\
\hline pGhost9 & $\mathrm{Erm}^{\mathrm{r}}$, ori pWV01, repA(Ts) & {$[27]$} \\
\hline $\begin{array}{l}\text { pMV158- } \\
\text { GFP }\end{array}$ & $\begin{array}{l}\text { pMV158 with the gene encoding } \\
\text { the green fluorescent protein }\end{array}$ & [24] \\
\hline $\begin{array}{l}\text { pTCV- } \\
\text { lac }\left(\mathrm{P}_{a p h A 3}\right)\end{array}$ & $\begin{array}{l}\text { Tet', ori ColE1, ori pAM } \beta 1 \text {, lac } Z \text { harboring } \\
\text { PaphA3 }_{\text {promoter }}\end{array}$ & {$[16]$} \\
\hline pVE14009 & $\begin{array}{l}\text { Erm }{ }^{r} \text {, ori pWV01, repA(Ts), with elrA } \\
\text { deletion }\end{array}$ & [4] \\
\hline pVE14047 & Ampr', pET2817 with $6 x$ His::ElrA & This work \\
\hline pVE14142 & $\begin{array}{l}\text { Ampr', Kan', ori p15A, } \\
\text { 'elrR-elrA' region }\end{array}$ & This work \\
\hline pVE14145 & $\begin{array}{l}\text { Ampr', Kan', ori p15A, } \\
\text { 'elrR-PaphA3::elrA' region }\end{array}$ & This work \\
\hline pVE14146 & $\begin{array}{l}\text { Erm', ori pWV01, repA(Ts), } \\
\text { 'elrR-P aphA3::elrA' region }\end{array}$ & This work \\
\hline pVE14178 & Amp', ori colE1, with elrA-E deletion & This work \\
\hline pVE14179 & Ampr', ori colE1, with elrB-E deletion & This work \\
\hline pVE14450 & $\begin{array}{l}\mathrm{Erm}^{\mathrm{r}} \text {, ori pWV01, repA(Ts), with elrB-E } \\
\text { deletion }\end{array}$ & This work \\
\hline pVE14455 & $\begin{array}{l}\text { Ampr, } \text { Kanr }^{r} \text {, ori p15A, with } \\
P_{a p h A 3}: \text { elrA-E deletion }\end{array}$ & This work \\
\hline pVE14456 & $\begin{array}{l}\text { Erm', ori pWV01, repA(Ts), with } \\
P_{a p h A 3}: \text { :lrA-E deletion }\end{array}$ & This work \\
\hline pVE14457 & $\begin{array}{l}\text { Erm', ori pWV01, repA(Ts), with } \\
P_{\text {aphA3:.:lrA deletion }}\end{array}$ & This work \\
\hline
\end{tabular}

(Ery) $30 \mu \mathrm{g} / \mathrm{ml}$; for E. coli, chloramphenicol $10 \mu \mathrm{g} / \mathrm{ml}$ and ampicillin $100 \mu \mathrm{g} / \mathrm{ml}$. DNA manipulations were performed as previously described [25]. 


\section{Cell line and culture conditions}

The RAW 264.7 mouse macrophage cell line (ATCC ${ }^{\bullet}$ TIB-71) was maintained in DMEM supplemented with $10 \%$ heat-inactivated fetal bovine serum (FBS) and $2 \mathrm{mM}$ l-glutamine [26]. For phagocytosis assays, cells were seeded at $0.5 \times 10^{6} /$ well into 12 -well tissue culture plates (TPP, Domique Dutscher, Brumath, France) and incubated overnight at $37^{\circ} \mathrm{C}$ under $6 \% \mathrm{CO} 2$. For microscopy experiments, cells were cultured in tissue culture plates containing poly-L-lysine pretreated coverslips for microscopy or on Lab-tek chamber slides (Nunc, Domique Dutscher). Comparative analysis of phagocytosis using either heatinactivated serum or serum-free media (MacrophageSFM, GIBCO, Invitrogen) did not show differences (data not shown). Thus, for practical reasons we decided to use heat-inactivated serum in all experiments of this work.

\section{Generation of anti-ElrA rat polyclonal antibodies}

Recombinant ElrA was purified to produce polyclonal rat anti-ElrA antibodies by Proteogenix (Oberhausbergen, France). Briefly, a DNA fragment encoding elrA was PCRamplified from E. faecalis chromosomal DNA using OEF275 and OEF276 primers (Table 2). The PCR product was digested with $\mathrm{BamHI} / \mathrm{Pci}$ and cloned into purified BamHI/NcoI-digested pET2817 vector backbone, resulting in plasmid VE14047 which was transformed into E. coli BL21( $\lambda$ DE3). For ElrA production and purification, the resulting recombinant strain was cultured at $25{ }^{\circ} \mathrm{C}$ and induced with $1 \mathrm{mM}$ of IPTG (isopropyl $\beta$-D-1-thiogalactopyranoside) for 5 hrs. Recombinant 6xHis::ElrA protein was purified under denaturing conditions on Ni-NTA columns using the QIAexpress kit (Qiagen, Courtaboeuf, France).

\section{Construction of mutant and over-expressing strains of $E$. faecalis}

The E. faecalis elrA gene is part of a five-gene operon elrA (OG1RF_12055), elrB (OG1RF_12054), elrC (OG 1RF_12053), elrD (OG1RF_12052), and elrE (OG1RF_ 12051) (Fig. 1), encoding putative surface proteins of unknown function. To circumvent the lack of ElrA production in vitro, we constructed a genetically modified $E$. faecalis strain harboring the constitutive promoter PaphA3 (hereafter named $\mathrm{P}^{+}$), instead of the native promoter, PelrA, upstream of the whole elr operon (i.e., elr $A-E$, Fig. 1). This genetically modified strain (called $\mathrm{P}^{+}$-elr $A-E$ ), was constructed by a double cross-over event using the pGhost9 plasmid [27]. Briefly, two overlapping fragments were PCR-amplified from E. faecalis OG1RF chromosomal DNA with primers OEF343/OEF344 and OEF345/OEF346 (Table 2). The two PCR products were then fused by PCR using the external primers OEF344/ OEF346, and the resulting product was cloned into purified XhoI-BamHI-digested pACYC177 vector, resulting in plasmid pVE14142. The PaphA3 promoter was PCR-amplified
Table 2 Primers used in this study

\begin{tabular}{|c|c|c|}
\hline Name & Sequence $5^{\prime}-3^{\prime}$ & $\begin{array}{l}\text { Source or } \\
\text { Reference }\end{array}$ \\
\hline OEF9 & TTGACCATCACGAGATACC & This work \\
\hline OEF13 & CTATCTTGGTCAAAAGAGCG & This work \\
\hline OEF15 & TATTCGATGTTGGCGTTGG & [4] \\
\hline OEF18 & GGAGGATGCGATTGTTTCG & [4] \\
\hline OEF212 & $\begin{array}{l}\text { CTCTTCTGCCGATGAAGTTT } \\
\text { CTGG }\end{array}$ & [4] \\
\hline OEF275 & $\begin{array}{l}\text { CAAACATGTTAGAAACGACC } \\
\text { GAAACAATCGC }\end{array}$ & This work \\
\hline OEF276 & $\begin{array}{l}\text { TTGGATCCACTCACCCCCT } \\
\text { ATTITGC }\end{array}$ & This work \\
\hline OEF343 & $\begin{array}{l}\text { GCGAATTCGAAGATCTGAG } \\
\text { AAAATATCAGGAGGTGAAG }\end{array}$ & This work \\
\hline OEF344 & $\begin{array}{l}\text { ATGGATCCAGACGGAGTAG } \\
\text { GTTATTTGC }\end{array}$ & This work \\
\hline OEF345 & $\begin{array}{l}\text { TTCTCAGATCTTCGAATTCGC } \\
\text { TGAATATCAACTGAAAATGGG }\end{array}$ & This work \\
\hline OEF346 & $\begin{array}{l}\text { ATCTCGAGTTGCGTATTTCG } \\
\text { GATTAGCC }\end{array}$ & This work \\
\hline OEF49 & CACGCTGTACGATCAGCAAC & This work \\
\hline OEF595 & CAATCCTAATAGCAATACACC & This work \\
\hline OEF596 & $\begin{array}{l}\text { GGTGTATTGCTATTAGGATTGT } \\
\text { GCCTGTTCATCATITACG }\end{array}$ & This work \\
\hline OEF598 & $\begin{array}{l}\text { CGAAACAATCGCATCCTCCTG } \\
\text { CCTGTTCATCATITIACG }\end{array}$ & This work \\
\hline Vlac1 & GTTGAATAACACTTATTCCTATC & [16] \\
\hline Vlac2 & CTTCCACAGTAGTTCACCACC & [16] \\
\hline
\end{tabular}

with primers Vlac1 and Vlac2 from pTCV-lac(PaphA3) plasmid [16]. An EcoRI-BamHI fragment, containing the PaphA3 promoter, was then cloned into EcoRI-BglIIdigested pVE14142 vector to obtain plasmid pVE14145. Then, a $2.3 \mathrm{~kb}$ XhoI-EaeI fragment from pVE14145 plasmid (containing the promoter and the targeted region) was cloned into pGhost9 vector to generate the final vector pVE14146. This plasmid was established in E. faecalis OG1RF strain and a markerless insertion of PaphA3 upstream of the $\operatorname{lr} A-E$ operon was performed as previously described [1]. Correct integration of PaphA3 into the chromosomal locus was confirmed by sequencing. All the following mutant constructs were performed using $\mathrm{P}^{+}-e \operatorname{lr} A-E$ strain as a recipient in order to have the same genetic background (Table 1 ). For the construction of a strain expressing only elrA under the control of PaphA3 promoter, a fused DNA fragment using primers OEF13/OEF595 and OEF596/OEF49 amplified from OG1RF strain DNA was cloned into pGEM-T easy vector (Promega) to generate pVE14179. A $4.5 \mathrm{~kb}$ PstI fragment was then cloned into PstI-digested pGhost9 to obtain plasmid pVE14450 and established in $\mathrm{P}^{+}$-elrA-E strain to obtain the $\mathrm{P}^{+}$-elrA- $\Delta e l r B-E$ strain. For 
the construction of a strain expressing elr operon lacking elrA, a $6.6 \mathrm{~kb}$ Bst/ApeI fragment from pVE14009 was cloned into Bst/ApeI-digested pVE14146 vector, resulting in pVE14457. This plasmid was established in $\mathrm{P}^{+}-e l r A-E$ strain to obtain the $\mathrm{P}^{+}-\Delta e l r A$ strain. To inactivate the whole elr operon (i.e., elrA-E), we first generated an in-frame deletion of the whole operon by PCR. For this, we used OEF15/ OEF18 and OEF598/OEF49 primers described for the first PCR. The two PCR products were fused by PCR using external primers OEF49/OEF15, and the resulting product was cloned into pGEM-T, resulting in plasmid pVE14178. A BstAPI/AatII 890bp DNA fragment from pVE14178 was then cloned into pVE14145 to generate pVE14455. The final plasmid was generated by cloning a $4.5 \mathrm{~kb}$ XhoI DNA fragment from pVE14455 vector into XhoIdigested pGhost9 to obtain pVE14456. This plasmid was established in $\mathrm{P}^{+}$-elrA-E strain and the resulting strain was named $\mathrm{P}^{+}-\Delta e l r A-E$. All expected modifications or deletions were confirmed by sequencing.

\section{Preparation of protein extracts, SDS gel electrophoresis, and immunoblot analysis}

Total protein extraction from bacteria, SDS-PAGE, and Western blot immunodetection were carried out using standard methods (24) with some modifications. Strains were grown at $37{ }^{\circ} \mathrm{C}$ overnight and then diluted 100-fold and grown under the same conditions to an $\mathrm{OD}_{600} \sim 1$. Protein crude extract was obtained by trichloroacetic acid (TCA) precipitation by mixing $800 \mu \mathrm{l}$ of bacterial culture with $200 \mu \mathrm{l}$ of ice cold TCA solution $(100 \% \mathrm{w} / \mathrm{v})$. The protein pellet was then obtained by centrifugation and recovered directly into SDS sample buffer. Anti-ElrA antibody was used at a dilution of 1:500 for Western blot immunodetection.

\section{RNA isolation and Northern blotting}

Total RNA was extracted as previously described [28]. Northern blots were performed on $40 \mu \mathrm{g}$ of total RNA separated on a $0.9 \%$ denaturing agarose gel as previously described [29]. Specific oligonucleotides OEF9 and OEF212 were used to detect elrA transcripts. Oligonucleotides were labelled with $[\gamma-32 \mathrm{P}]-\mathrm{ATP}$ and T4 polynucleotide kinase (NEB Biolabs) according to the recommendations of the manufacturer (NEB Biolabs). Analysis was performed from RNA extracted from two independent experiments.

\section{Phagocytosis assay with RAW macrophages}

Fluorescent E. faecalis were grown on GM17 plates containing erythromycin (GM17-Ery), with a single colony subsequently being selected and grown overnight in GM17-Ery broth. A $100 \mu \mathrm{l}$ aliquot was then transferred into $10 \mathrm{ml}$ of fresh GM17-Ery and incubated until cultures reached an $\mathrm{OD}_{600} \sim 1$. Bacteria were then pelleted by centrifugation, washed three times with PBS, and adjusted to a concentration of $1 \times 10^{9} \mathrm{CFU} / \mathrm{ml}$ in supplemented DMEM. The number of bacteria present in each suspension was confirmed by plating onto solid GM17-Ery.

For phagocytosis experiments, adherent RAW cells were infected with fluorescent E. faecalis at a multiplicity of infection (MOI) of 100:1 (bacterium/cell ratio). After 30 min of interaction, cells were washed twice with PBS, recovered with cell dissociation buffer (GIBCO, Invitrogen), washed again, and finally fixed in $3 \%$ paraformaldehyde (PFA) solution. Fluorescence of RAW cells due to infecting bacteria was detected by a flow cytometer in the FL-1 channel. The phagocytosis index (PI) was calculated using the percent of fluorescent macrophages after E. faecalis wild-type (WT) strain infection and applying the following formula: $\mathrm{PI}=$ (percent of fluorescent macrophages after infection X 100 /percent of fluorescent macrophages after WT infection) [30, 31]. Results are expressed as the mean \pm SEM from three independent experiments usually performed in duplicate or triplicate.

\section{Bacterial adhesion assay}

To separate adhesion from subsequent steps of phagocytosis, cells were pretreated $30 \mathrm{~min}$ with $1 \mu \mathrm{g} / \mathrm{ml}$ of cytochalasin $\mathrm{D}(\mathrm{Cyt} \mathrm{D})$, an actin polymerization inhibitor, as described [17]. A CytD (1000X) stock solution in DMSO was prepared according to manufacturer's recommendations and stored at $-20{ }^{\circ} \mathrm{C}$. DMEM supplemented medium (see above) was used to dilute stock solution. RAW cells were seeded at $1 \times 10^{6} /$ well into 6 -well tissue culture plates (TPP, Dominique Dutscher) and incubated $\mathrm{O} / \mathrm{N}$ at $37{ }^{\circ} \mathrm{C}$ under $6 \% \mathrm{CO} 2$. Macrophages pre-treated with CytD were first washed twice with fresh medium and then infected at a MOI of 100:1, similar to phagocytosis analysis above; CytD-untreated and uninfected macrophages were used as negative controls. Fluorescence in RAW cells due to infecting bacteria was detected by flow cytometry. Adhesion Index $(\mathrm{AI})=$ (percent of $\mathrm{GFP}^{+}$macrophages pre-treated with CytD, after infection by the $E$. faecalis mutant strain X 100/percent of $\mathrm{GFP}^{+}$macrophages pre-treated with CytD after WT infection).

\section{Fluorescence and electron microscopy}

Raw macrophages were seeded in 12-well cell culture plates on a glass slide and infected with GFP-labeled $E$. faecalis wild-type (WT) or $\mathrm{P}^{+}$-elrA-E strains at a MOI of 1:100, with uninfected macrophages serving as negative control. After $30 \mathrm{~min}$ of interaction, macrophages were washed twice with PBS, fixated and immunolabeled with Streptococcus group D antiserum (BD Diagnostics, Le Pont de Claix, France) as previously described [4]. Fluorescence was examined using a Carl Zeiss microscope (Axiovert $200 \mathrm{M}$, in the ApoTome mode) at MIMA2 
platform (INRA, Jouy en Josas). Images were processed with Axiovision version 4.6 (Carl Zeiss).

Imaging of bacterial-cells interaction was performed using a Hitachi S-4500 scanning electron microscope (SEM) at the MIMA2 imaging platform. Macrophages were seeded in 12-well cell culture plates and infected with either $E$. faecalis wild-type (WT) or $\mathrm{P}^{+}$-elrA-E strains at a MOI of 1:100, with uninfected macrophages serving as negative control. After $30 \mathrm{~min}$ of interaction, macrophages were washed twice with PBS, recovered with cell dissociation buffer (GIBCO, Invitrogen), washed again, and suspended in a fixative solution and treated as previously described [32].

Preparation of bacterial samples for transmission and scanning electron microscopy was performed as previously described [32,33]. Thin-sections and negative-stains were observed with a Zeiss EM902 electron microscope operated at $80 \mathrm{kV}$ (MIMA2 - UR 1196 Génomique et Physiologie de la Lactation, INRA, plateau de Microscopie Electronique, 78352 Jouy-en-Josas, France). Microphotographies were acquired using MegaView III CCD camera and analyzed with the ITEM software (Eloise SARL, Roissy CDG, France).

\section{Microbial adhesion to solvents}

Microbial adhesion to solvents (MATS) analysis was carried out as described previously by Bellon-Fontaine and collaborators [21]. In brief, a single colony of each of the $E$. faecalis strains studied was subcultured four times in BHI and harvested at stationary phase. Bacterial cells were centrifuged at $5000 \times \mathrm{g}$ for $8 \mathrm{~min}$ and washed twice in $0.15 \mathrm{M} \mathrm{NaCl}$ and re-suspended to a final $\mathrm{OD}_{400} \sim 0.8$. Bacterial suspensions $(2.4 \mathrm{ml})$ were vortexed for $1 \mathrm{~min}$ with $0.4 \mathrm{ml}$ of highest purity grade chloroform (SigmaAldrich), hexadecane (Sigma-Aldrich), ethyl acetate (Merck), or decane (Merck). The emulsion was left to stand for 20 min to allow complete phase separation, and the $\mathrm{OD}_{400}$ of $1 \mathrm{ml}$ from the aqueous phase was measured. Affinity of the cells for each solvent (\% affinity) $=\left(\left(\mathrm{OD}_{\mathrm{f}}-\mathrm{OD}_{\mathrm{i}}\right) /\right.$ $\left.\mathrm{OD}_{\mathrm{i}}\right) \times 100$ where $\mathrm{OD}_{i}$ is the initial optical density of the bacterial suspension before mixing with the solvent, and $\mathrm{OD}_{f}$ the final absorbance after mixing and phase separation. Analysis was performed twice in triplicate.

\section{Mouse peritonitis model}

The mouse experiments were approved by the Institutional Animal Use and Care Committee at the Università Cattolica del Sacro Cuore, Rome, Italy (permit number Z21, 1 November 2010), and authorized by the Italian Ministry of Health, according to the Legislative Decree 116/92, which implemented the European Directive 86/ $609 /$ EEC on laboratory animal protection in Italy. Animal welfare was routinely checked by veterinarians of the Service for Animal Welfare.
Virulence of strains OG1RF, $\triangle e l r A$, and $\mathrm{P}^{+}$-elrA-E was tested as described previously [4]. The inoculum size was confirmed by determining the number of CFU on brain heart infusion agar. Each inoculum was 10 -fold diluted in $25 \%$ sterile rat fecal extract prepared from a single batch as previously described [34]. Groups of 10 ICR outbred mice (Harlan Italy Srl, San Pietro al Natisone, Italy) were challenged intraperitoneally with $1 \mathrm{ml}$ of each bacterial inoculum, housed five per cage, and fed ad libitum. A control group of mice was injected with $25 \%$ sterile rat fecal extract only. Survival was monitored every 3 to $6 \mathrm{~h}$. In another set of experiments, groups of mice were killed $24 \mathrm{~h}$ postinfection, and livers and spleens were removed, weighed, homogenized, and serially diluted in saline solution for colony counts.

\section{Statistical analysis}

Statistics were performed using GraphPad Prism (Version 4.00 for Windows, GraphPad Software, San Diego California, USA). One-way analysis of variance (ANOVA) was followed by Dunnett's multiple-comparison test when comparing multiple groups for one factor. For animal experiments, survival estimates were constructed by the Kaplan-Meier method and compared by log rank analysis, and comparisons with $P$ values of $<0.05$ were considered to be significant.

\section{Additional file}

Additional file 1: Figure S1. Bacterial adhesion assay. RAW macrophages
were pretreated with cytochalasin D (CytD) or not (-) before infection
with E. faecalis strains WT and $\mathrm{P}^{+}$-elrA-E expressing GFP. After 30 min of
interaction, cells were washed twice with PBS, recovered with cell
dissociation buffer. GFP positives macrophages were detected by flow
cytometry. Graphs represent green fluorescence intensity. Results are
representative of two independent experiments. In the absence of CytD
pretreatment, the population of GFP-labeled macrophages infected
with the $\mathrm{P}^{+}$-elrA-E strain (55.5 \%) is decreased compared to the
macrophages infected with the WT strain (86.6 \%). CytD is known to
inhibit actin rearrangement and blocks bacterial entry. To establish
whether differential GFPlabeling of macrophages resulted from
adhesion or entry defect of strain $\mathrm{P}^{+}$-elrA-E, similar experiment was
performed on macrophages pre-treated with CytD. When infected with
the WT strain, the population of GFP-labeled pre-treated macrophages
(77.9\%) slightly decreased compared to untreated ones. This observation
indicates that the majority of the GFP-labeled macrophages detected harbor
adherent GFP-bacteria at their surface. In contrast, the intensity and the
population of GFP-labeled pre-treated macrophages infected with the
$P^{+}$-elrA-E strain (28.4 \%) decreased drastically compared to untreated
ones, indicating that P ${ }^{+}$-elrA-E bacteria adhered less efficiently to
macrophages.

Competing interests

The authors declare that they have no competing interests.

\section{Authors' contributions}

NGCP designed, performed, and interpreted in vitro experiments, and contributed to write the manuscript. RD and SG constructed the bacterial strains. CL and RM carried out RNA experiments, KP performed Western Blot experiments, SC and TM performed electron microscopy. FB performed 
mouse experiments and BP, MS and LRG designed animal experiments and helped writing the manuscript. PL critically revised the manuscript for intellectual content. PS designed and coordinated the study and wrote the manuscript. All authors read and approved the final manuscript.

\section{Acknowledgements}

We thank A. Navickas and F. Wessner for technical support on MATS assays and RNA extractions, and P. Adenot and R. Fleurot of the Platform MIMA2 for access to the Apotome microscope. We also thank P. Lee, A. Gruss, D. Lereclus, C. Archambaud and S. Aymerich for critical revision of the manuscript. We are thankful to M. Mangan for careful reading of the manuscript for the English editing. This work was supported by the Institut National de la Recherche Agronomique. R.D. was supported by a fellowship from the Région Ile-de-France in the framework of the Dim MalinF.

\section{Author details}

${ }^{1}$ INRA, UMR1319 Micalis, Jouy-en-Josas, France. ${ }^{2}$ AgroParisTech, UMR1319 Micalis, Jouy-en-Josas, France. ${ }^{3}$ Institute of Microbiology, Università Cattolica del Sacro Cuore, Rome, Italy. ${ }^{4}$ Institute of Public Health (Section of Hygiene), Università Cattolica del Sacro Cuore, Rome, Italy. ${ }^{5}$ Current address: INRA, Unité d'Immuno-Allergie Alimentaire, iBiTecS/SPI, Gif-sur-Yvette, France.

\section{Received: 14 January 2015 Accepted: 14 May 2015}

Published online: 25 May 2015

\section{References}

1. Brinster S, Furlan S, Serror P. C-terminal WxL domain mediates cell wall binding in Enterococcus faecalis and other gram-positive bacteria. J Bacteriol. 2007:189(4):1244-53.

2. Siezen R, Boekhorst J, Muscariello L, Molenaar D, Renckens B, Kleerebezem M. Lactobacillus plantarum gene clusters encoding putative cell-surface protein complexes for carbohydrate utilization are conserved in specific gram-positive bacteria. BMC Genomics. 2006;7:126.

3. Galloway-Pena JR, Liang X, Singh KV, Yadav P, Chang C, La Rosa SL, et al. The identification and functional characterization of $W \times L$ proteins from Enterococcus faecium reveal surface proteins involved in extracellular matrix interactions. J Bacteriol. 2015;197(5):882-92.

4. Brinster S, Posteraro B, Bierne $H$, Alberti A, Makhzami S, Sanquinetti M, et al Enterococcal Leucine-Rich Repeat-Containing Protein Involved in Virulence and Host Inflammatory Response. Infect Immun. 2007;75(9):4463-71.

5. Dumoulin R, Cortes-Perez N, Gaubert S, Duhutrel P, Brinster S, Torelli R, et al. Enterococcal Rgg-Like Regulator ElrR Activates Expression of the elrA Operon. J Bacteriol. 2013;195(13):3073-83.

6. Shepard BD, Gilmore MS. Differential expression of virulence-related genes in Enterococcus faecalis in response to biological cues in serum and urine. Infect Immun. 2002;70(8):4344-52.

7. Knodler LA, Celli J, Finlay BB. Pathogenic trickery: deception of host cell processes. Nat Rev Mol Cell Biol. 2001;2(8):578-88.

8. Gentry-Weeks CR, Karkhoff-Schweizer R, Pikis A, Estay M, Keith JM. Survival of Enterococcus faecalis in Mouse Peritoneal Macrophages. Infect Immun. 1999;67(5):2160-5.

9. Verneuil N, Sanguinetti M, Le Breton Y, Posteraro B, Fadda G, Auffray Y, et al. Effects of the Enterococcus faecalis hypR gene encoding a new transcriptional regulator on oxidative stress response and intracellular survival within macrophages. Infect Immun. 2004;72(8):4424-31.

10. Baldassarri $L$, Bertuccini L, Creti R, Filippini P, Ammendolia MG, Koch $S$, et al. Glycosaminoglycans mediate invasion and survival of Enterococcus faecalis into macrophages. J Infect Dis. 2005;191(8):1253-62.

11. Coburn PS, Baghdayan AS, Dolan GT, Shankar N. An AraC-type transcriptional regulator encoded on the Enterococcus faecalis pathogenicity island contributes to pathogenesis and intracellular macrophage survival. Infect Immun. 2008;76(12):5668-76.

12. Thurlow LR, Thomas VC, Fleming SD, Hancock LE. Enterococcus faecalis capsular polysaccharide serotypes $C$ and $D$ and their contributions to host innate immune evasion. Infect Immun. 2009;77(12):5551-7.

13. Hancock LE, Gilmore MS. The capsular polysaccharide of Enterococcus faecalis and its relationship to other polysaccharides in the cell wall. Proc Natl Acad Sci U S A. 2002;99(3):1574-9.

14. Teng F, Jacques-Palaz KD, Weinstock GM, Murray BE. Evidence that the enterococcal polysaccharide antigen gene (epa) cluster is widespread in
Enterococcus faecalis and influences resistance to phagocytic killing of $E$. faecalis. Infect Immun. 2002;70(4):2010-5.

15. Prajsnar TK, Renshaw SA, Ogryzko NV, Foster SJ, Serror P, Mesnage S Zebrafish as a Novel Vertebrate Model To Dissect Enterococcal Pathogenesis. Infect Immun. 2013;81(11):4271-9.

16. Poyart C, Trieu-Cuot P. A broad-host-range mobilizable shuttle vector for the construction of transcriptional fusions to $\beta$-galactosidase in Gram-positive bacteria. FEMS Microbiol Lett. 1997;156(2):193-8.

17. Elliott JA, Winn Jr WC. Treatment of alveolar macrophages with cytochalasin D inhibits uptake and subsequent growth of Legionella pneumophila. Infect Immun. 1986;51(1):31-6.

18. Gaillard JL, Berche P, Mounier J, Richard S, Sansonetti P. In vitro model of penetration and intracellular growth of Listeria monocytogenes in the human enterocyte-like cell line Caco-2. Infect Immun. 1987:55(11):2822-9.

19. Travier L, Guadagnini S, Gouin E, Dufour A, Chenal-Francisque V, Cossart P, et al. ActA promotes Listeria monocytogenes aggregation, intestinal colonization and carriage. PLoS Pathog. 2013:9(1):e1003131.

20. Courtney HS, Ofek I, Penfound T, Nizet V, Pence MA, Kreikemeyer B, et al. Relationship between expression of the family of $M$ proteins and lipoteichoic acid to hydrophobicity and biofilm formation in Streptococcus pyogenes. PLoS One. 2009;4(1):e4166.

21. Bellon-Fontaine M-N, Rault J, van Oss CJ. Microbial adhesion to solvents: a novel method to determine the electron-donor/electron-acceptor or Lewis acid-base properties of microbial cells. Colloids Surf B: Biointerfaces. 1996;7(1-2):47-53

22. Garsin DA, Frank KL, Silanpaa J, Ausubel FM, Hartke A, Shankar N, Murray BE. Pathogenesis and Models of Enterococcal Infection. In: Enterococci: From Commensals to Leading Causes of Drug Resistant Infection. Edited by Gilmore MS, Clewell DB, Ike Y, Shankar N. Boston: Massachusetts Eye and Ear Infirmary; 2014

23. Reid SD, Montgomery AG, Voyich JM, DeLeo FR, Lei B, Ireland RM, et al. Characterization of an extracellular virulence factor made by Group A Streptococcus with homology to the Listeria monocytogenes internalin family of proteins. Infect Immun. 2003;71(12):7043-52

24. Nieto C, Espinosa M. Construction of the mobilizable plasmid pMV158GFP, a derivative of pMV158 that carries the gene encoding the green fluorescent protein. Plasmid. 2003;49(3):281-5

25. Sambrook J, Fritsch EF, Maniatis T. Molecular cloning: a laboratory manual. 2nd ed. Cold Spring Harbor, N. Y: Cold Spring Harbor Laboratory Press; 1989.

26. Orman KL, Shenep JL, English BK. Pneumococci stimulate the production of the inducible nitric oxide synthase and nitric oxide by murine macrophages. J Infect Dis. 1998;178(6):1649-57.

27. Maguin E, Duwat P, Hege T, Ehrlich D, Gruss A. New thermosensitive plasmid for gram-positive bacteria. J Bacteriol. 1992;174(17):5633-8.

28. Fouquier d'Herouel A, Wessner F, Halpern D, Ly-Vu J, Kennedy SP, Serror P, Aurell E, Repoila F: A simple and efficient method to search for selected primary transcripts: non-coding and antisense RNAs in the human pathogen Enterococcus faecalis. Nucleic acids research 2011;39(7):e46.

29. Mandin P, Repoila F, Vergassola M, Geissmann T, Cossart P. Identification of new noncoding RNAs in Listeria monocytogenes and prediction of mRNA targets. Nucleic Acids Res. 2007;35(3):962-74

30. Pils S, Schmitter T, Neske F, Hauck CR. Quantification of bacterial invasion into adherent cells by flow cytometry. J Microbiol Methods. 2006;65(2):301-10.

31. Van Amersfoort ES, Van Strijp JA. Evaluation of a flow cytometric fluorescence quenching assay of phagocytosis of sensitized sheep erythrocytes by polymorphonuclear leukocytes. Cytometry. 1994;17(4):294-301.

32. Oxaran V, Ledue-Clier F, Dieye Y, Herry JM, Pechoux C, Meylheuc T, et al. Pilus biogenesis in Lactococcus lactis: molecular characterization and role in aggregation and biofilm formation. PLoS One. 2012;7(12):e50989.

33. Rigottier-Gois L, Madec C, Navickas A, Matos RC, Akary-Lepage E, Mistou MY, et al. The Surface Rhamnopolysaccharide Epa of Enterococcus faecalis Is a Key Determinant of Intestinal Colonization. J Infect Dis. 2015;211(1):62-71

34. Pai SR, Singh KV, Murray BE. In vivo efficacy of the ketolide ABT-773 (cethromycin) against enterococci in a mouse peritonitis model. Antimicrob Agents Chemother. 2003:47(8):2706-9.

35. Dunny GM, Brown BL, Clewell DB. Induced cell aggregation and mating in Streptococcus faecalis: evidence for a bacterial sex pheromone. Proc Natl Acad Sci U S A. 1978;75(7):3479-83.

36. Gibson TJ. Studies on the Epstein-Barr virus genome, PhD Thesis. Cambridge, UK: University of Cambridge; 1984 
37. Studier FW, Moffatt BA. Use of bacteriophage T7 RNA polymerase to direct selective high-level expression of cloned genes. J Mol Biol. 1986;189(1):113-30

38. Rose RE. The nucleotide sequence of pACYC177. Nucleic Acids Res. 1988;16(1):356

39. Chastanet A, Fert J, Msadek T. Comparative genomics reveal novel heat shock regulatory mechanisms in Staphylococcus aureus and other Gram-positive bacteria. Mol Microbiol. 2003;47(4):1061-73.

Submit your next manuscript to BioMed Central and take full advantage of:

- Convenient online submission

- Thorough peer review

- No space constraints or color figure charges

- Immediate publication on acceptance

- Inclusion in PubMed, CAS, Scopus and Google Scholar

- Research which is freely available for redistribution 